\title{
Experimental results on the solid organic fertilizer machine MG 5
}

\author{
Vasilica Ştefan ${ }^{1 *}$, Raluca Sfî̀u and Lucreţia Popa ${ }^{1}$ \\ ${ }^{1}$ INMA Bucharest, 6 Ion Ionescu de la Brad, Bucharest, Romania
}

\begin{abstract}
This paper is the first of a series of works devoted to the general issues of organic fertilizer spreading machines. Although the working process of solid organic fertilizer machines does not contain a large number of random constituents, however, the basic component, the material administered, gives the random characteristic of the process. In addition, another random component that influences the working process of the machine is the interaction of the work organ that performs the tearing and distribution of the scattered material with this material, as well as the movement of the fragments of material onto the surface of the device. A third random component is the movement of the material scattered into the atmosphere. The fragments of scattered material exhibit shape irregularities due to fragments during dislocation from the mass of feed material and due to particle collisions while moving into air until the contact with the soil. Therefore, the phenomenon of spraying the organic fertilizer on the layer from the soil surface is, as a whole, a random process. Consequently, it is logical to have experimental research prioritized in the study of the work on the distribution of solid organic fertilizers. The role of this article is to present the experimental results, some conclusions and to prefigure several theoretical or theoretical-empirical research directions. The results contained in this article are basics in all the other essays related to the topic machine.
\end{abstract}

\section{Introduction}

Processes of administration of some substances on agricultural land are an important component of most agricultural crop technologies. Through these processes, nutrients are ensured for the crops concerned, protection against pests or parasitic vegetation, the agricultural potential of the land is restored.

Mechanized processes for the administration of organic fertilizers are an important component of soil fertilization for agricultural use (and not only), especially in the context of a current (perhaps shy but existent) return to organic farming.

Most studies referring to precision farming applications address to chemical fertilizer. The motion of the particle on spinning disks equipped with pitched straight or curved vanes are described in $[1,2,3,4]$. In $[5,6,7]$ the manure distribution process is studied (the interaction between manure particle and spreading equipment, the influence of the working parameters

\footnotetext{
*Corresponding author: valle_vali@yahoo.com
} 
overs the distribution uniformity, numerical model for the flow in land application). In [8] the authors studied the relative motion over a rough surface of a rotary vertical axis helicoid and the movement equation were given and solved by numerical methods.

Generally, the organic fertilizers are found in the form of conglomerates in different physical and chemical states and contain many organic substances with very different properties, so that a characterization as acceptable in terms of physical (especially chemical) is very difficult to obtain. The first condition required to obtain an even distribution of the product on soil surface is to correlate manure properties with the characteristics of the land application equipment.

It is obvious that an attempt to estimate the coefficients of friction and viscosity of the contact between the particles of such a material and the metal of the fragmentation and throwing device is an extremely demanding test. The dependence of these properties on the chemical-physical composition of the material (organic fertilizer: compost or fermentation manure, for example) implies a multidisciplinary approach: chemistry, physics, mechanics, biology. It is difficult to carry out such a complex research to describe the dependence by the parameters mentioned above on the material humidity, ambient temperature, atmospheric pressure, concentrations of the main components of the material being administered. In other words, scattered scraps of scrap do not allow a good assimilation of them with the material points of Newtonian mechanics. Fragments of scattered material have appreciable areas of contact with the air and, in addition, in a large range of values, which makes the friction force with air an important component in their displacement into the atmosphere. The interaction between the particles thrown by the fragmentation and scattering apparatus is a very difficult factor to consider in a deterministic model. Even for a stochastic model, the movement of fragments of organs discharged by the organic fertilizer machine is very difficult and, given the very probably, the few effectively results, the effort required is hard to sustain.

Under these circumstances, the initial experimental study appears to be the only realistic solution, since that the theoretically-empirical and theoretical developments may occur later when some basic elements of the process will be established.

\section{Material and method}

To perform the experiments, the solid organic fertilizer machine MG 5 was used, fig. 1 and 2 , the scraper of which consists of four vertical rotors, arranged at an angle of $10^{\circ}$ to the vertical, in order to allow the material of the dump to be easily entrained according to the angle of its natural slope, fig. 1. Each rotor is made up of a central shaft on which there are 3 spirals at the end of which there are provided cutting and grinding blades of the material, and at the bottom there are provided centrifugal blades which allow the scraping of the remaining material in the conveyor or material squeegees missed by the first spiral of the rotor.

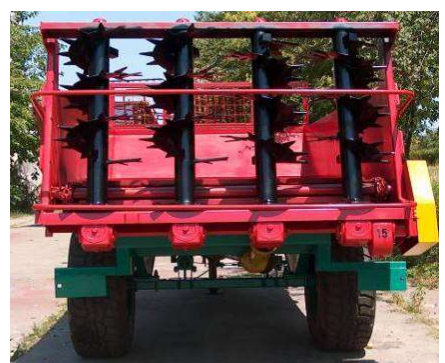

Fig. 1. Organic fertilizer spreader MG 5, rear view.

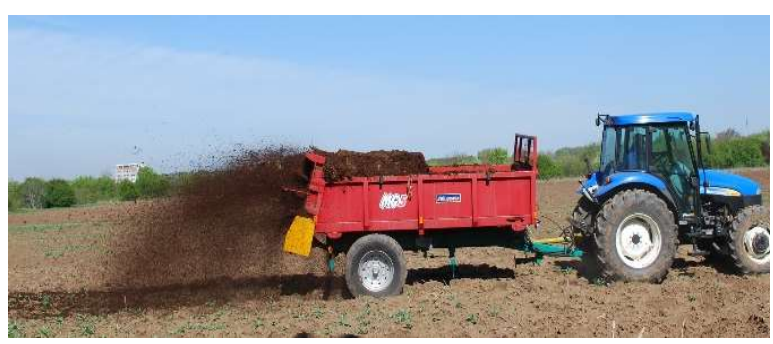

Fig. 2. Organic fertilizer spreader MG 5, lateral view during work.

The scraper is driven by power take-off (PTO) and has a transmission ratio of 1: 1 .

The exploitation tests were carried out with compost and semi-fermented manure, distributed on stubble. The amount of fertilizer per hectare that can be dispensed by the MG- 
5 has varied depending on the aggregate displacement speed, conveyor speed, and fertilizer characteristics.

The rotors speed in the distribution device component is correlated with the engine power of the power source. Three rotational speeds of 360, 440 and $530 \mathrm{rpm}$ were used, corresponding to 1500,2000 or $2200 \mathrm{rpm}$ respectively of the tractor engine.

Three feed rates for compost (weighing $510 \mathrm{~kg} / \mathrm{m} 3,52 \%$ humidity) were chosen, namely 6,15 and $26 \mathrm{~kg} / \mathrm{s}$ corresponding to three speeds of the scraper conveyor, namely 0.006 , 0.0143 and $0.025 \mathrm{~m} / \mathrm{s}$. For semi-fermented manure we used material with a mass density of $800 \mathrm{~kg} / \mathrm{m} 3$, humidity $75 \%$, the working speeds at the same conveyor speeds were 10,23 and $40 \mathrm{~kg} / \mathrm{s}$.

For collecting the samples, geotextile material of dimension $\mathrm{L}$ x 1 $=18 \mathrm{x} 1 \mathrm{~m}$, transversely arranged in the direction of movement of the machine, was used, Fig. 4.

After work shift, the distributed material was collected in a transverse plane on $1 \mathrm{~m} 2$ surfaces using a square metal frame with the $1 \mathrm{~m}$ side, fig. 3, 4. The samples were collected in plastic bags, numbered and weighed to the precision 1 gram.

The results obtained under the conditions shown have served to calculate the qualitative working indicators.

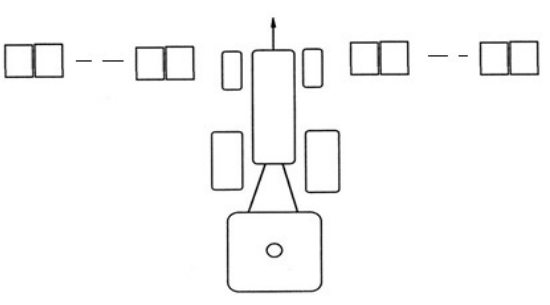

Fig. 3. The sketch of the work of the fertilizer machine, and of the sampling

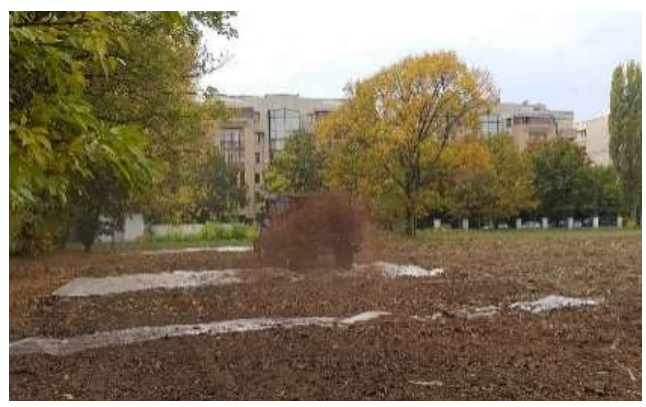

Fig. 4. The fertilizer machine in working time

\subsection{Statistical analysis of experimental data}

Experimental data analysis is useful not only to make some appreciation of the machine performance but also to get useful suggestions in mathematical modelling, especially interpolation of experimental data.

In Table 1 are specify the main machine parameters, which have been varied in the experimental research done physically. It can be noticed that the parameters of the garbage spreader geometry did not change: the characteristics of the rotors (length, spiral pitch, radius), spatial arrangement.

Table 1. The list of parameters and their physical dimensions

\begin{tabular}{|c|c|c|c|c|}
\hline Name & Notation & $\mathbf{M}$ & $\mathbf{L}$ & $\mathbf{T}$ \\
\hline The coordinate of the measurement point ${ }^{*}$ & $x$ & 0 & 1 & 0 \\
\hline Rotors speed & $\omega$ & 0 & 0 & -1 \\
\hline The fertilizer machine flow rate & $q$ & 1 & 0 & -1 \\
\hline The angle of inclination of the rotors & $\beta$ & 0 & 0 & 0 \\
\hline Density of scattered material & $\rho$ & 1 & -3 & 0 \\
\hline Linear density of scattered material & $\sigma$ & 1 & -2 & 0 \\
\hline Working speed of the car & $v$ & 0 & 1 & -1 \\
\hline
\end{tabular}

*The coordinate of the measuring point on the axis perpendicular to the working direction, originating in the projection on the ground of the intersection between the axis of the working direction and the axis perpendicular to it. 
Of the parameters considered in the experimental research (and obviously, varied), the parameter $\sigma$ is, from a qualitative point of view, the most important. This parameter gives the linear distribution of the material scattered by the scraping device with which the machine is equipped. The measurement procedure is described in Chapter 1.The parameter $\sigma$ is called linear density of distributed material and is measured in a $1 \mathrm{~m}$ wide rectangular band behind the machine over a $13 \mathrm{~m}$ long, measured in a transverse plane to the trajectory of the fertilizer machine, and is measured in $\mathrm{kg} / \mathrm{m}^{2}$.The variation of the linear density of the distributed material, in the plane of the application surface, must be less than 15\% (see SR ISO 5690-1: 95) from the mean. Using this function is can estimate the effective working width, and the optimal working regime of the machine.

\subsection{The descriptive properties of the distribution (descriptive statistics, estimators)}

The elementary statistical analysis includes the values of the reference estimators of the linear density distribution of the scattered material. The experimental data containing 629 records in the form shown in Fig. 5.

\begin{tabular}{|c|c|c|c|c|c|c|c|c|}
\hline 4 & A & B & C & D & $E$ & $\mathrm{~F}$ & G & $\mathrm{H}$ \\
\hline 1 & Mass & \begin{tabular}{|c|} 
Coordinate \\
$\mathrm{X}$ \\
\end{tabular} & \begin{tabular}{|c|} 
Coordinate \\
$\mathrm{Y}$ \\
\end{tabular} & \begin{tabular}{|c|}
$\begin{array}{c}\text { Rotational } \\
\text { speed }\end{array}$ \\
\end{tabular} & $\begin{array}{l}\text { Feed } \\
\text { flow }\end{array}$ & $\begin{array}{c}\text { Tractor } \\
\text { speed }\end{array}$ & $\begin{array}{c}\text { Inclination } \\
\text { angle }\end{array}$ & $\begin{array}{c}\text { Bulk } \\
\text { density }\end{array}$ \\
\hline 2 & $\sigma$ & $\mathbf{x}$ & $y$ & $\omega$ & $q$ & v & B & $\gamma$ \\
\hline 3 & kg & $m$ & $\mathrm{~m}$ & $\mathrm{rot} / \mathrm{min}$ & $\mathrm{kg} / \mathrm{s}$ & $\mathrm{m} / \mathrm{s}$ & $\circ$ & $\mathrm{kg} / \mathrm{m} 3$ \\
\hline 4 & 0.114 & -4.5 & -0.5 & 360 & 6 & 1 & 15 & 510 \\
\hline 5 & 0.254 & -3.5 & -0.5 & 360 & 6 & 1 & 15 & 510 \\
\hline 6 & 0.687 & -2.5 & -0.5 & 360 & 6 & 1 & 15 & 510 \\
\hline 7 & 0.897 & -1.5 & -0.5 & 360 & 6 & 1 & 15 & 510 \\
\hline 8 & 0.782 & -0.5 & -0.5 & 360 & 6 & 1 & 15 & 510 \\
\hline
\end{tabular}

Fig. 5. Sequence of records stored in the Excel database

The values of the calculated estimators are given in the Table 2 .

Table 2. Statistical estimators

\begin{tabular}{|l|r|}
\hline \multicolumn{1}{|c|}{ Statistical estimators $^{\dagger}$} & Values \\
\hline Minimum value & 0.015 \\
\hline Maximum value & 7.740 \\
\hline Arithmetic mean & 1.843 \\
\hline Geometric mean & 1.142 \\
\hline Harmonic mean & 0.505 \\
\hline Mode & 1.325 \\
\hline Median & 1.382 \\
\hline Kurtosis & 0.774 \\
\hline Skewness & 1.107 \\
\hline Square root of the population variance & 1.565 \\
\hline Square root of the sample variance & 1.566 \\
\hline Variance & 2.449 \\
\hline The sample variance & 2.452 \\
\hline
\end{tabular}

The large difference between the minimum and maximum values of the linear density of the scattered material is due to the fact that in the experimental and measuring process the extreme areas from which the material was distributed in insignificant amounts were taken

${ }^{\dagger}$ For estimators definitions see, for example $[10,11]$. 
into consideration, areas which are not included in the actual work width of the machine. The average value of the linear density of the scattered material gives an approximation of the mean value applicable with this car, the most probable value of the studied parameter, under the given conditions, [12].In addition to this mean value, even higher and lower values are possible, depending on the needs, and these can be achieved using of operable adjustments for varied parameters in the experiment (Table 1).

Harmonic mean is more useful when looking for the estimation of a phenomenon rate and the parameter has of the specified physical size. Geometric mean is used when more variables occur in multiplicative combinations. The mode, is the most likely value of the random variable studied. Median is the so-called middle value (for which the number of samples with higher values is equal to the number of samples with lower values).Kurtosis is an estimator of the distribution form, which for normal distribution has zero value, being positive for higher and sharper distribution distributions than normal and negative distribution otherwise $[13,14]$.In the case of the distribution analyzed in this paper, the distribution is leptokurtic. Skewness (asymmetry) refers to the distribution symmetry and has positive or negative values, as the mode is located to the left of the median and the middle to the right of the fashion, respectively the fashion is to the right and the average to the left of the median,[15]. Also, in this case, the asymmetry has the value of 1.107 , so the mean distribution is asymmetric with deviation to the left of the middle of the fashion. The average square deviation and the sampled average square deviation (a better estimate of population variation), [13], differs very few. The average square deviation is slightly lower than the average (arithmetic mean) of the population. As a variant, the standard mean deviation is a measure of spreading the distribution values around the average of the same distribution, [12].

The distribution of the linear density samples of the scattered material after the sample mass is given numerically in fig. 6 and in fig. 7 in percentage.

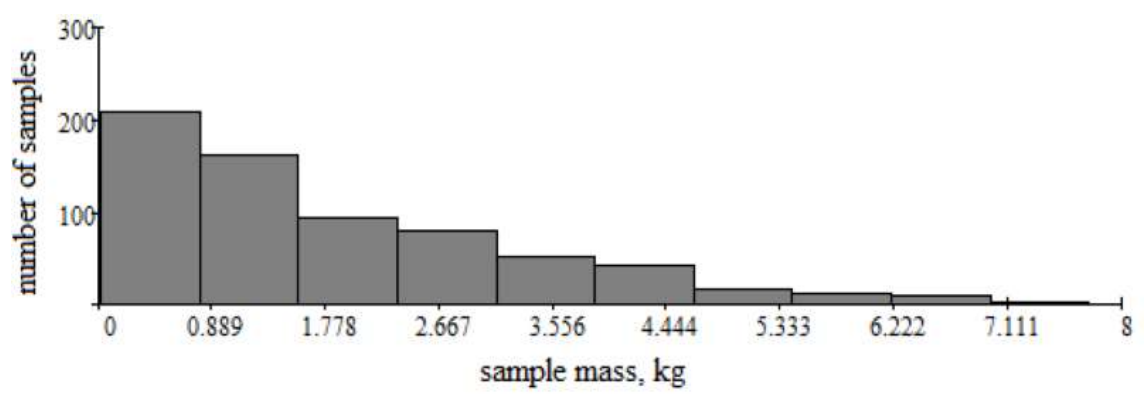

Fig. 6. Histogram of distribution $\sigma$, after sample mass.

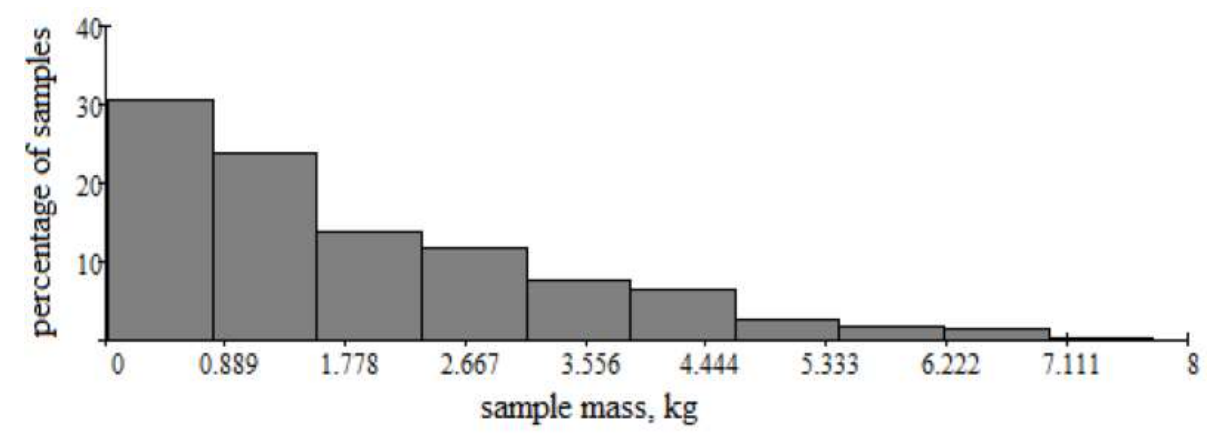

Fig. 7. Percent histogram of the distribution $\sigma$, after mass of samples 


\subsection{Correlations}

The relations between the distribution of the linear density of the scattered material and the various experimentally varied parameters results from Table 3 , which contains the values of covariance and correlation. The covariance and correlation are calculated according to [13]. Covariance and correlation (called correlation coefficient and correlation coefficient in some publications) are statistical parameters that highlight the relationship of dependence between two random variables [10]. The two statistical sizes show, from our point of view, the same phenomenon: a tight connection between the linear density of the scattered material and the mass flow rate provided by the machine, $q$, respectively, the density of the scattered material, $\rho$. The other parameters that were taken into account in the experimental work are insignificantly related to the main quality parameter of the machine, the linear density of the scattered material, $\sigma$.

This result shows that any attempt to model the mathematical link between $\sigma$, as the main quality parameter of the fertilizer spreader machine and the process input and control parameters, must first take into account the two parameters highlited by the covariance and correlation: $q, \rho$.

Table 3 Values of the covariance and correlation of linear density of the scattered material with experimentally varied parameters

\begin{tabular}{|l|c|c|c|c|c|c|}
\hline & $\boldsymbol{x}$ & $\boldsymbol{\omega}$ & $\boldsymbol{q}$ & $\boldsymbol{v}$ & $\boldsymbol{\beta}$ & $\boldsymbol{\rho}$ \\
\hline Covariance $\boldsymbol{\sigma}$ with: & -0.297 & -0.256 & 9.894 & -0.024 & -0.006 & 61.230 \\
\hline Correlation $\boldsymbol{\sigma}$ with: & -0.055 & -0.023 & 0.565 & -0.053 & -0.057 & 0.270 \\
\hline
\end{tabular}

It can be seen that the average linear density of the scattered material by the fertilizer machine is $1.843 \mathrm{~kg} / \mathrm{m}^{2}$, approximately $18 \mathrm{t} / \mathrm{ha}$. For the fertilizers used in the experiments, the literature provides for the application rate of 10-40 $\mathrm{t} / \mathrm{ha}$, for compost which have density $500 \mathrm{~kg} / \mathrm{m}^{3}$ and 20-80 t/ha, for the waste which have density of $800 \mathrm{~kg} / \mathrm{m}^{3}[16,17]$.

\subsection{Granulometric quality of scattered material}

Among the performance of the organic fertilizer spreader, an important place is the granulometric quality of the scattered material, that is, what in terms of specialty is called the degree of crushing. This aspect of the organic fertilizer spreading process has been studied partially in [18]. The main results are summarized in Table 4.

Table 4 Values of spread width and shredding degree

\begin{tabular}{|c|c|c|c|c|c|}
\hline Material type & $\begin{array}{c}\text { Rotative speed } \\
\text { of spreading } \\
\text { apparatus } \\
{[\mathbf{r p m}]}\end{array}$ & $\begin{array}{c}\text { Maximum } \\
\text { distribution } \\
\text { width } \\
{[\mathrm{m}]}\end{array}$ & $\begin{array}{c}\text { Total } \\
\text { mass of } \\
\text { sample } \\
{[\mathrm{kg}]}\end{array}$ & $\begin{array}{c}\text { Mass of } \\
\text { particles } \\
\text { sized of }< \\
\mathbf{6 c m}[\mathrm{kg}]\end{array}$ & $\begin{array}{c}\text { Shredding } \\
\text { degree } \\
{[\%]}\end{array}$ \\
\hline \multirow{3}{*}{$\begin{array}{c}\text { Fermented } \\
\text { manure }\end{array}$} & 365 & 8.5 & 14.08 & 10.78 & 76.56 \\
\cline { 2 - 6 } & 445 & 10 & 15.95 & 12.52 & 78.49 \\
\hline \multirow{3}{*}{ Compost } & 530 & 13 & 20.05 & 17.56 & 87.58 \\
\cline { 2 - 6 } & 365 & 9 & 17.79 & 16.85 & 94.71 \\
\cline { 2 - 6 } & 445 & 11.5 & 19.23 & 18.12 & 94.22 \\
\hline
\end{tabular}

The particle distribution in the scattered material is given in Table 5. 
Table 5 Particle size distribution of tested materials

\begin{tabular}{|c|c|c|c|c|c|c|c|c|}
\hline \multirow[b]{2}{*}{ Material } & \multirow{2}{*}{$\begin{array}{c}\text { Rotational } \\
\text { speed } \\
{[\mathrm{rpm}]}\end{array}$} & \multirow{2}{*}{$\begin{array}{c}\text { Total } \\
\text { sample } \\
\text { mass } \\
{[\mathrm{kg}]}\end{array}$} & \multicolumn{6}{|c|}{ Particle size distribution of each material fraction $[\mathrm{kg}]$} \\
\hline & & & $>6 \mathrm{~cm}$ & $4-6 \mathrm{~cm}$ & $2-4 \mathrm{~cm}$ & $1-2 \mathrm{~cm}$ & $0,5-1 \mathrm{~cm}$ & $<0.5 \mathrm{~cm}$ \\
\hline $\begin{array}{c}\text { Fermented } \\
\text { manure }\end{array}$ & 530 & 3.45 & 0.250 & 0.300 & 0.446 & 0.954 & 0.492 & 1.008 \\
\hline Compost & 530 & 4.82 & 0 & 0.245 & 0.520 & 0.745 & 1.360 & 1.950 \\
\hline
\end{tabular}

By using the data in Table 4, information on the maximum spread width and the degree of crushing can be obtained, depending on the speed of rotation of the spreader. In fig. 11 and 12 are given the dependences, of the maximum spread width, respectively of the degree of crushing, by the speed of rotation of the apparatus. Because the experimental points available were only three, we preferred to calculate only the linear regression (linear dependence). If $b_{\max }$ is the maximum working width, and $g_{m}$, is the degree of crushing of the scattered material, and $\omega$, the angular rotation speed of the scattering apparatus, then the linear dependence equations whose graphical representation is given in fig. 11 and 12, are written as follows:

$$
b_{\max }(\omega)=0.261 \omega-1.719
$$

in case the scattered material is fermented manure,

$$
b_{\max }(\omega)=0.289 \omega-2.031
$$

in case the scattered material is the compost,

$$
g_{m}(\omega)=0.642 \omega+50.858
$$

in case the scattered material is fermented manure,

$$
g_{m}(\omega)=0.34 \omega+81.823
$$

in case the scattered material is the compost. The functions (1) - (4) are plotted in fig. 8 and 9. In the same figures are also show the distribution of experimental data (measured directly).

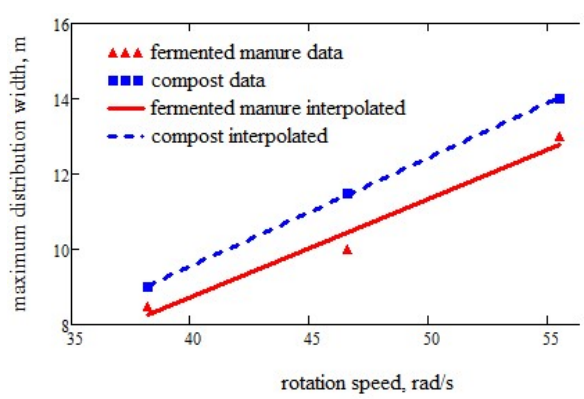

Fig. 8 The dependence of the maximum spread width, by the rotation speed of the appliance

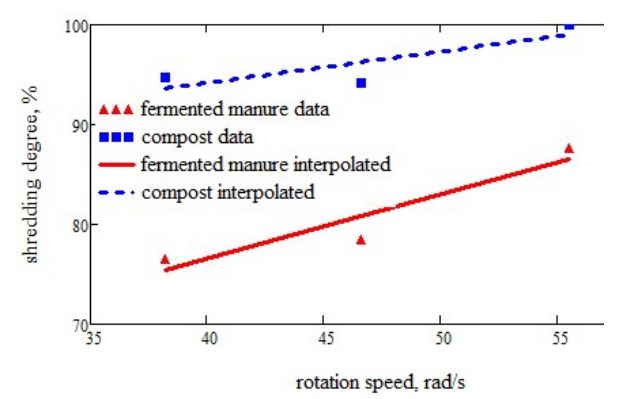

Fig. 9 The dependence of the degree of crushing of scattered material, by the speed of rotation of the rotors

As can be seen from the tabular data and graphs presented, the maximum spread width and the crushing rate increase, together with increasing the rotational speed of the spreader. Increasing the rotation speed of the scatter means also increasing the energy consumption of the machine. 


\section{Conclusions}

Some of the conclusions have already been expressed immediately after the results are presented. The most important will be repeated in this chapter.

The minimum and maximum values of the scattered material quantities on the measured work width of 0 to $13 \mathrm{~m}$ allow the range of MG 5 fertilizer machine application rate to be set between 10 and $80 \mathrm{t} / \mathrm{ha}$.

The variance of the linear distribution density of the scattered material is approximately $2.45 \mathrm{~kg} / \mathrm{m}^{2}$. This value is not yet relevant to the quality of the machine's uniformity of administration because it is calculated for all the work regimes achieved $(v, q, \beta, \rho)$. The variance will be calculated as a measure of the uniformity of spreading material for each working regime. The lowest value of the variance relative to the mean value (desirable is that it is the standard indicated by scientific criteria) of the spreaded material amount denotes satisfactory uniformity, but a limit of their ratio is only conventional.

An information on the uniformity of the distribution of the material also gives the kurtosis estimator. For the uniformity to be the best, the value of this estimator must be negative (with a maximum ceiling below that of the normal distribution). For the time being, but only for the whole lot of experimental recordings, kurtosis has a small but positive value, therefore, on the perpendicular section on the fertilizer machine feed axis, the linear distribution density of the administered material shows a fairly visible peak.

Also, useful information on the uniformity of the linear density of the scattered material is given by its histograms. These must be interpreted in relation to the imposed rule, and then the surface of the field where the amount of material administered is excess and where it is less than what is required can be estimated. It is also necessary to take into account the tolerances admitted by the farmers specialists. In any case, it should be taken into account that the non-uniformity of the linear density of the material administered may be the cause of the crop irregularity.

The skewness factor has a positive value and denotes a deviation to the left of the median of the distribution pattern $\sigma$ in the transverse direction of the machine. This is information that suggests better adjustment of the drive mechanisms as well as the geometry of the rotors placement.

The values of the correlation between the linear density of the administered material and the other recorded parameters show that its most intense dependence is on the feed rate and the bulk density of the material administered.

The quality of the work of the organic fertilizer machines is also expressed by the degree of crushing of the material used. The small study in this paper about this feature shows that the degree of crushing increases with the rotation speed of the rotors, which increases also the maximum working width of the machine (which is not, however, the actual work width).

In view of these results, separate analysis is planned on work regimes, and firstly to develop statistical mathematical models on which to estimate and optimize an effective working width of the fertilizer machine. Also, based on these models, a study of the factors involved influence is possible, as well as an economic study (work capacity and energy consumption) are made.

\section{Acknowledgement}

This work was supported by a grant of the Romanian Research and Innovation Ministry, through Programme 1 - Development of the national research-development system, subprogramme 1.2 - Institutional performance - Projects for financing excellence in RDI, contract no. 16PFE. 


\section{References}

1. Xie S.Y., Yu T., Chen T.H., Yang Z.R., Yang L., Yang M.J., Design and experimental study of a rapeseed broadcast spreader of screw-drop type, INMATEH Agricultural Engineering Journal, 55, 19-26, 2018.

2. Popa L., Ştefan V., Andrei L.V., Guran G., Research regarding the construction of a chemical and amendments fertilizer machine MA 3,6, Scientific Papers (INMATEH), I, 5459, 2009.

3. Kobets A.S., Naumenko M.M., Ponomarenko N.O., Kharytonov M.M., Velychko O.P., Yaropud V.M., Design substantiation of the three-tier centrifugal type mineral fertilizers spreader, INMATEH Agricultural Engineering Journal, 53, 13-20, 2017.

4. Popa L., Pirnă I., Vlăduţ V., Ştefan V., Researches Concerning the achievement of a machine for spreading low rates of chemical fertilizers", The 8th International Symposium "PROSPECTS FOR THE 3rd MILLENNIUM AGRICULTURE", University of Agricultural Sciences and Veterinary Medicine, Cluj-Napoca, 66, 441-447, 2009.

5. Stefan V., Cârdei P., Popa L., Experimental results on the solid organic fertilizer machine $\quad \mathrm{GG}$ 5, April 2019. [Online]. Available: https://www.researchgate.net/publication/332112021_Experimental_results_on_the_solid_ organic_fertilizer_machine_MG_5. [Accessed 22 april 2019].

6. Landry H., Piron E., Ägnew J.M., Lague C., Roberge M., Performances of conveying systems for manure spreaders and effects of hopper geometry on output flow, Applied Engineering in Agriculture, 21, 159-166, 2005.

7. Landry H., Thirion F., Lague C., Roberge M., Numerical modelling of the flow of organic fertilizers in land application equipment, Computers and Electronics in Agriculture, 51, 35-53, 2006.

8. Duhovnik J., Benedičič J., Bernik R., Analysis and design parameters for inclined rotors used for manure dispersal on broadcast spreaders for solid manures, Transactions of the ASAE, 47, 1389-1404, 2004.

9. Pylypaka S.F., Klendii M.B., Klendii O.M., Particle motion over the surface of a rotary vertical axis helicoid. INMATEH Agricultural Engineering Journal, 51, 15-28, 2017.

10. V. Bobancu, N. Mihaileanu, S. Gheorghita, A. Brezuleanu, A. Stefanescu, T. Balanescu. Dictionar de matematici generale. Bucuresti: Editura Enciclopedica Romana. (1974).

11. MathSoft Engineering \& Education, I. Mathcad User's Guide with Reference Manual Mathcad 2001 Professional. Cambridge: MathSoft Engineering \& Education, Inc. (2001).

12. M. G. Bulmer. Principles of Statistics. Dover: doverpublication. (1979).

13. Statistic How To. Retrieved from

https://www.statisticshowto.datasciencecentral.com/probability-and-statistics/statisticsdefinitions/kurtosis-leptokurtic-platykurtic/ .(2019, March 1).

14. Engineering Statistic Handbook. (2019, March 13). Retrieved from https://www.itl.nist.gov/div898/handbook/eda/section3/eda35b.html.

15. D. Jain. Retrieved from https://codeburst.io/2-important-statistics-terms-you-need-toknow-in-data-science-skewness-and-kurtosis-388fef94eeaa/ .(2019, March 13.

16. V. Scripnic, P. Babiciu. Masini Agricole. Bucuresti: Editura Ceres. 1979.

17. R. Majdar, V. Davidescu. Agrochimie. Bucuresti: USAMV. 2009.

18. V. Ştefan, R. Ciupercă, L. Popa, A. Nedelcu, G. Lazăr, A.S. Petcu, A. Zaica, The influence of physical characteristics of solid organic fertilizers on quality of land spreading. INMATEH - Agricultural Engineering, 46, 77-84, 2015. 